Article

\title{
Biomass to Syngas: Modified Stoichiometric Thermodynamic Models for Downdraft Biomass Gasification
}

\author{
Hafiz Muhammad Uzair Ayub, Sang Jin Park and Michael Binns * \\ Department of Chemical and Biochemical Engineering, Dongguk University, 30, Pildong-ro 1-gil, Jung-gu, \\ Seoul 04623, Korea; uzairayub003@gmail.com (H.M.U.A.); sjpark@dongguk.edu (S.J.P.) \\ * Correspondence: mbinns@dongguk.edu
}

Received: 11 September 2020; Accepted: 13 October 2020; Published: 15 October 2020

check for updates

\begin{abstract}
To help meet the global demand for energy and reduce the use of fossil fuels, alternatives such as the production of syngas from renewable biomass can be considered. This conversion of biomass to syngas is possible through a thermochemical gasification process. To design such gasification systems, model equations can be formulated and solved to predict the quantity and quality of the syngas produced with different operating conditions (temperature, the flow rate of an oxidizing agent, etc.) and with different types of biomass (wood, grass, seeds, food waste, etc.). For the comparison of multiple different types of biomass and optimization to find optimal conditions, simpler models are preferred which can be solved very quickly using modern desktop computers. In this study, a number of different stoichiometric thermodynamic models are compared to determine which are the most appropriate. To correct some of the errors associated with thermodynamic models, correction factors are utilized to modify the equilibrium constants of the methanation and water gas shift reactions, which allows them to better predict the real output composition of the gasification reactors. A number of different models can be obtained using different correction factors, model parameters, and assumptions, and these models are compared and validated against experimental data and modelling studies from the literature.
\end{abstract}

Keywords: biomass gasification; stoichiometric; modelling; optimization; thermodynamics; methanation reaction; water gas shift reactions

\section{Introduction}

To meet the growing global demand for energy, various sources of energy are being considered and utilized. One of the possible renewable sources is biomass, and different technologies are being developed for extracting fuels and energy from various types of biomass feedstock. The main thermochemical routes include gasification, combustion, pyrolysis, and liquefaction [1,2]. Gasification is a promising thermochemical conversion route for the production of combustible clean fuel $[3,4]$. This reacts the biomass feed with an oxidizing agent to produce hydrogen $\left(\mathrm{H}_{2}\right)$ and carbon monoxide (CO), as well as carbon dioxide $\left(\mathrm{CO}_{2}\right)$, methane $\left(\mathrm{CH}_{4}\right)$, and nitrogen $\left(\mathrm{N}_{2}\right)$. In addition to these compounds, contaminants such as sulphur dioxide $\left(\mathrm{SO}_{2}\right)$, sulphur trioxide $\left(\mathrm{SO}_{3}\right)$, nitric oxide $(\mathrm{NO})$, nitrogen dioxide $\left(\mathrm{NO}_{2}\right)$, ammonia $\left(\mathrm{NH}_{3}\right)$, and hydrogen sulphide $\left(\mathrm{H}_{2} \mathrm{~S}\right)$ may also be found, as well as some quantities of unreacted carbon (char), tar, and ash [5-7]. In addition, dioxins and furans may also be produced, toxic emissions which can be reduced through the use of hydrogasification using, for example, hydrogen from electrolysis [8].

Generally, the composition of the syngas depends upon the gasifier type, gasification agent, and operating conditions [4,9]. Compared to other gasifier technologies, many researchers have 
reported that downdraft gasifiers are the most promising option for small-scale power generation plants $(<10$ MWth) due to their low tar contents and efficient design [10]. The tar production in downdraft gasifiers is relatively low because they are designed such that the tars formed are combusted before leaving with product gases [10].

The modelling of biomass gasification generally involves the formulation and solving of sets of equations, including mass and energy balances, in addition to either rate-based or equilibrium-based expressions to determine the effect of the reactions occurring. To simplify this approach, various assumptions can be made and correlations can be utilized relating to experimentally measured properties (e.g., feed composition and operating conditions). The more complex approaches include the use of computational fluid dynamics (CFD) models [11-13] and kinetic rate expression models [14-16], which require knowledge of the reaction and diffusion parameters and potentially require relatively longer computational times than the simpler modelling methods available. Excluding the more complex models based on their rate expressions, the different possible simplified models include the following:

(1) Stoichiometric thermodynamic equilibrium;

(2) Non-stoichiometric thermodynamic equilibrium;

(3) Stoichiometric thermodynamic equilibrium with empirical correction factors;

(4) Non-stoichiometric thermodynamic equilibrium with empirical correction factors;

(5) Empirical correlations.

These simpler models include thermodynamic equilibrium models (1-2), which assume that the reactions reach an equilibrium state. While it is known that, experimentally, reactions do not necessarily reach equilibrium, this type of model can still give a reasonable approximation of the performance for certain reactor designs and operating conditions [1]. There are two categories of equilibrium model, including stoichiometric models (1), which calculate the equilibrium constants for individual reactions in the process, and non-stoichiometric models (2), which minimize the Gibbs free energy of the possible reaction products. Both categories of model should then give similar predictions of the gas product composition given the operating conditions of the gasification. In stoichiometric models $[17,18]$, the equilibrium constants are calculated for each reaction involved in gasification. Meanwhile, in non-stoichiometric models [19] the minimization of Gibbs free energy method is used.

In order to correct the errors associated with assuming the system reaches equilibrium, a number of studies have suggested the inclusion of correction factors which shift the equilibrium in order to more closely reflect reality. These correction factors are empirically determined based on fitting with experimental results. So far, these have only been applied to stoichiometric thermodynamic equilibrium models (3) [20-23].

In addition, the simplest possible models (type 5) are those which directly correlate the gasification product composition using correlations developed from either model predictions or from experimental data. For example, Gautam et al. [24] developed an equilibrium model and then used the model predictions to fit linear correlations, relating the outlet syngas composition to the biomass feed composition. Pradhan et al. [25] also developed the correlation by using 50 biomass samples via a linear regression model. They also compared the regression model results with the equilibrium model. These models did not include the mass balance and energy balance equations and various important parameters such as the temperature and equilibrium ratio.

In previous studies [1,4], many researchers have developed thermodynamic equilibrium models to predict the syngas composition of downdraft biomass gasifiers from different biomass feedstocks $[9,17,20,21,26,27]$. For example, Zainal et al. [27] constructed a thermodynamic equilibrium model based on the equilibrium constant of the methane formation reaction and water gas shift reaction to predict the syngas composition. They analysed the effect of parameters such as the initial water content and the gasification temperature at a fixed equivalence ratio. They constructed the model considering the general global gasification reaction, assuming complete carbon conversion. In order 
to consider the carbon conversion efficiency, Azzone et al. [20] developed a thermodynamic model where it is assumed that complete carbon conversion is not possible and that char can be seen in a significant amount at the end of the process. Therefore, they introduced the $\alpha$ factor, which is a function of the equivalence ratio. Jarungthammachote and Dutta [21] conducted a modification of the equilibrium model based on the 11 experiment results presented by Zainal et al. [28], Jayah et al. [26], and Altafini et al. [29]. They generated two correction factor from the 11 experiments and modelled the results. The equilibrium constant of the water gas shift reaction and methanation is multiplied by 0.91 and 11.28, respectively [21]. They modified the model assuming the complete carbon conversion at the end of the gasification process. Aydin et al. and Yucel et al. [23] modified the stoichiometric equilibrium model by also considering the tar and char. They estimated the equilibrium temperature and also multiplied the equilibrium constants by the correction factors, which are the function of the equivalence ratio, gasification temperature, and equilibrium temperature. Although they used the large amounts of experimental data, there is still a need to reduce the error by introducing more accurate correction factor models. Pradhan et al. [25] presented a comparison of five different models based on different equilibrium reaction constants for biomass gasification. They showed that the models considering the methanation reaction and water gas shift reaction gave the best composition of syngas with respect to the other models. Costa et al. [22] developed a modified equilibrium model by including the three reactions and three correction factors, and these correction factor showed higher errors compared to the modified equilibrium models based on the water gas shift reaction and methanation reaction. Although the above-mentioned research shows some improvements in the prediction accuracy of the model results at the specific gasification conditions, there is a need to optimize the model correction factors based on the real experiment results for the prediction of accurate syngas gas compositions.

In this study, four stoichiometric thermodynamic equilibrium models for biomass gasification have been developed by considering models:

- With or without a carbon conversion factor;

- With or without correction factors used to multiply with the equilibrium constants,

The carbon conversion factor is found through a correlation (or set to 1). Optimization is used collecting original published experimental results to find optimal values for the correction factors. After that, the different models are validated with different experimental results and compared with some other stoichiometric thermodynamic models from the literature.

\section{The Stoichiometric Thermodynamic Equilibrium Model}

To develop the stoichiometric thermodynamic equilibrium model, the following assumptions have been considered:

- The biomass feedstock consists of carbon, hydrogen, oxygen, and nitrogen;

- Alkalis and metal contents in the biomass are neglected;

- Ash is considered as inert;

- The syngas consists of $\mathrm{H}_{2}, \mathrm{CO}, \mathrm{CO}_{2}, \mathrm{CH}_{4}, \mathrm{H}_{2} \mathrm{O}$, and $\mathrm{N}_{2}$;

- The negligible amount of tar is produced from the downdraft gasifier;

- The feedstock of biomass and the air enters the gasifier at the temperature of $25^{\circ} \mathrm{C}$, and the gasifier pressure is $101.13 \mathrm{kPa}$;

- The system is considered as adiabatic and there is not any heat loss from the system;

- All the reactions inside the gasifier achieved the equilibrium;

- All the gases of the developed system are considered as ideal gases;

- $\mathrm{N}_{2}$ is not participating in any chemical reaction. 
The following global gasification reaction is considered:

$$
\begin{gathered}
\mathrm{CH}_{a} \mathrm{O}_{b} \mathrm{~N}_{c}+w \mathrm{H}_{2} \mathrm{O}+m \mathrm{O}_{2}+\rho m \mathrm{~N}_{2} \\
=(1-\alpha) \mathrm{C}+x_{1} \mathrm{H}_{2}+x_{2} \mathrm{CO}+x_{3} \mathrm{CO}_{2}+x_{4} \mathrm{H}_{2} \mathrm{O}+x_{5} \mathrm{CH}_{4}+\rho m \mathrm{~N}_{2} .
\end{gathered}
$$

In Equation (1), the molecular formula of biomass is $\mathrm{CH}_{a} \mathrm{O}_{b} \mathrm{~N}_{c}$. The nitrogen to oxygen molar ratio is denoted by $\rho$ (e.g., 3.76 for standard air). In order to consider complete carbon conversion, the $\alpha$ factor had introduced [20]. The subscripts $a, b$, and $c$ are obtained from the given ultimate analysis of biomass. The terms of $x_{1}, x_{2}, x_{3}, x_{4}, x_{5}$ and $(1-\alpha)$ are the mole fractions of $\mathrm{H}_{2}, \mathrm{CO}, \mathrm{CO}_{2}, \mathrm{H}_{2} \mathrm{O}, \mathrm{CH}_{4}$ and unreacted carbon (char), respectively. Meanwhile, $\mathrm{m}$ is mole fraction of $\mathrm{O}_{2}$ participating as a reactant, and $\mathrm{w}$ is the available moisture content of the biomass feedstock. There are a total of seven unknowns in Equation (1), which are $x_{1}, x_{2}, x_{3}, x_{4}, x_{5}, \alpha, m$. To determine the unknowns, we need seven equations which are obtained from the mass and energy balances of the biomass gasification system. These equations are listed below.

Carbon balance:

$$
(1-\alpha)+x_{2}+x_{3}+x_{5}=1
$$

Hydrogen balance:

$$
a+2 w=2 x_{1}+2 x_{4}+4 x_{5} .
$$

Oxygen balance:

$$
b+w+2 m=x_{2}+2 x_{3}+x_{4} .
$$

The methanation and water gas shift reactions are considered for the thermodynamic equilibrium modeling $[21,27,30]$. Their equilibrium constants can be written in terms of their mole fraction, as given below:

$$
K_{1, \mathrm{CH}_{4}}=\frac{\left[x_{5}\right]}{\left[x_{1}\right]^{2}} X_{t}
$$

where $X_{t}$ denotes the total molar concentration of the product gas:

$$
\begin{gathered}
X_{t}=x_{1}+x_{2}+x_{3}+x_{4}+x_{5}+\rho m, \\
K_{2, w g s}=\frac{\left[x_{1} x_{3}\right]}{\left[x_{2} x_{4}\right]} .
\end{gathered}
$$

The equilibrium constants $K_{1, \mathrm{CH}_{4}}$ and $K_{2, w g s}$ are calculated from the Gibbs free function, as given below:

$$
-R T \ln K=\Delta G,
$$

where $\Delta G$ is the function of enthalpy of formation, as given below:

$$
\Delta G=\Delta H-T \Delta S
$$

For the specified gasification system $\Delta S_{f}^{0}$ and $\Delta H_{f}^{0}$ can be calculated as follows:

$$
\begin{gathered}
\Delta H_{f}^{0}(T)=\Delta H_{f}^{0}(298.15)+\int_{298.15}^{T_{i n}} C_{p j} d T, \\
\Delta S_{f}^{0}(T)=\Delta S_{f}^{0}(298.15)+\int_{298.15}^{T_{i n}} \frac{C_{p j}}{T} d T, .
\end{gathered}
$$

The specific heat capacity $C_{p j}(T)$ can be calculated as [31]:

$$
C_{p j}(T)=A o+B T+C T^{2}+D T^{-2} .
$$


The Enthalpy balance equations for the adiabatic gasification system can be written as:

$$
\begin{gathered}
H_{\text {reactants }}=H_{\text {products }} \\
H_{\text {reactants }}=H_{f_{-} \text {biomass }}^{0}+\sum_{j=1}^{N}\left(H_{f_{-} j}^{0}+\int_{298.15}^{T_{i n}} C_{p j} d T\right) . \\
H_{\text {products }}=\sum_{i=1}^{M}\left(H_{f_{-} i}^{0}+\int_{298.15}^{T_{\text {out }}} C_{p i} d T\right) .
\end{gathered}
$$

Moreover, in order to consider the actual conditions for the biomass gasification system, the complete carbon conversion is not possible. Therefore, the carbon participating in the gasification reactions can be calculated as [20]:

$$
\alpha=0.32+0.82\left(1-e^{-\mathrm{ER} / 0.229}\right) \cdot 0.21<\mathrm{ER}<0.4,
$$

where the equivalence ration (ER) can be described as the ratio of actual air entering into the gasifier to the theoretical stoichiometric required air for complete combustion. Mathematically, ER can be expressed as follows:

$$
\mathrm{ER}=\frac{m}{1+\frac{a}{4}-\frac{b}{2}}
$$

Finally, the heat of the formation of biomass feedstock, $H_{f_{-} \text {biomass }}^{0}$ can be determined from experiments or by correlation and is given as [32]:

$$
H_{f_{-} \text {biomass }}^{0}=\text { HHVbiomass }+H_{f_{\mathrm{CO} 2}}^{0}+\frac{B}{2}\left(H_{f_{\mathrm{H} 2 \mathrm{O}}}^{0}\right) \text {. }
$$

The higher heating value $(H H V)$ of biomass feedstock can be calculated as [33],

$$
\text { HHVbiomass }=0.3491 \mathrm{C}+1.1783 \mathrm{H}+0.1005 \mathrm{~S}-0.1034 \mathrm{O}-0.0151 \mathrm{~N}-0.0211 \text { Ash },
$$

where $C, H, S, O, N$, and Ash are the mass percentages of biomass components from the ultimate analysis. The lower heating value ( $L H V$ ) of the end product (syngas) can be estimated by the correlation, given as the following [34]:

$$
L H V \text { gas }=x_{1} L H V H_{2}+x_{2} L H V C O+x_{5} L_{H V C H},
$$

where $L H V H_{2}=10.78 \mathrm{MJ} \mathrm{N} / \mathrm{m}^{3} ; L H V C O=12.63 \mathrm{MJ} \mathrm{N} / \mathrm{m}^{3} ; L H V \mathrm{LH}_{4}=35.88 \mathrm{MJ} \mathrm{N} / \mathrm{m}^{3}$.

\section{Model Implementation}

There are a total of seven unknowns, $x_{1}, x_{2}, x_{3}, x_{4}, x_{5}, \alpha$, and $m$, which represent the product gas mole fraction, the carbon participating in the reaction, and the amount of oxygen required for the biomass gasification. Therefore, seven equations are needed to find the unknowns, which are three mass balance equations (Equations (2)-(4)), two equilibrium constant equations (Equations (5) and (7)), one energy balance equation (Equation (13)), and one equivalence ratio as a function of the oxygen required for biomass gasification (Equation (17)). This system of linear and non-linear equations has been solved by Newton Raphson methods. After that, the equilibrium constant correction factors for the water gas shift reaction and methanation reaction are generated and optimized in MATLAB. The models have been formulated and implemented in MATLAB, which is widely used for programming calculations. The model algorithm is shown in Figure 1, which includes evaluating equations and calculating gas compositions, which are updated as part of the Newton-Raphson method until the equations are satisfied. Four different models have been developed for comparison. 
The details of these models can be seen in Table 1. The correction factors for the water gas shift reaction and methanation reaction are applied in model (M3) and model (M4). In M3, the correction factors are 0.9617 and 8.5216 for the water gas shift reaction and methanation reaction, respectively. Meanwhile, in M4 the correction factors are 0.8331 and 4.7451 for the water gas shift reaction and the methanation reaction, respectively. As mentioned in the previous section, Jarungthammachote and Dutta [21] proposed that the correction factor for the equilibrium constant of the water gas shift reaction and methanation are multiplied by 0.91 and 11.28 , respectively, but they did not consider the carbon conversion factor. They generated the correction factor just by using the 11 experimental studies without any optimization. Azzone et al. [20] considered only the carbon conversion factor without any correction factor for the water gas shift reaction and methanation reaction. In this study, this gap is overcome by developing the M3 and M4 models with the correction factors for the water gas shift reaction and methanation reaction by considering the complete and uncomplete carbon conversion. Thus, Equations (5) and (7) can be described with the correction factors as follows:

$$
\begin{aligned}
& \operatorname{Cr} 1 K_{1, \mathrm{CH}_{4}}=\frac{\left[x_{5}\right]}{\left[x_{1}\right]^{2}} X_{t} \\
& \mathrm{Cr} 2 K_{2, w g s}=\frac{\left[x_{1} x_{3}\right]}{\left[x_{2} x_{4}\right]},
\end{aligned}
$$

where $\mathrm{Cr} 1$ and $\mathrm{Cr} 2$ are the correction factors used in the M3 and M4 models for the methanation and water gas shift reactions, respectively.

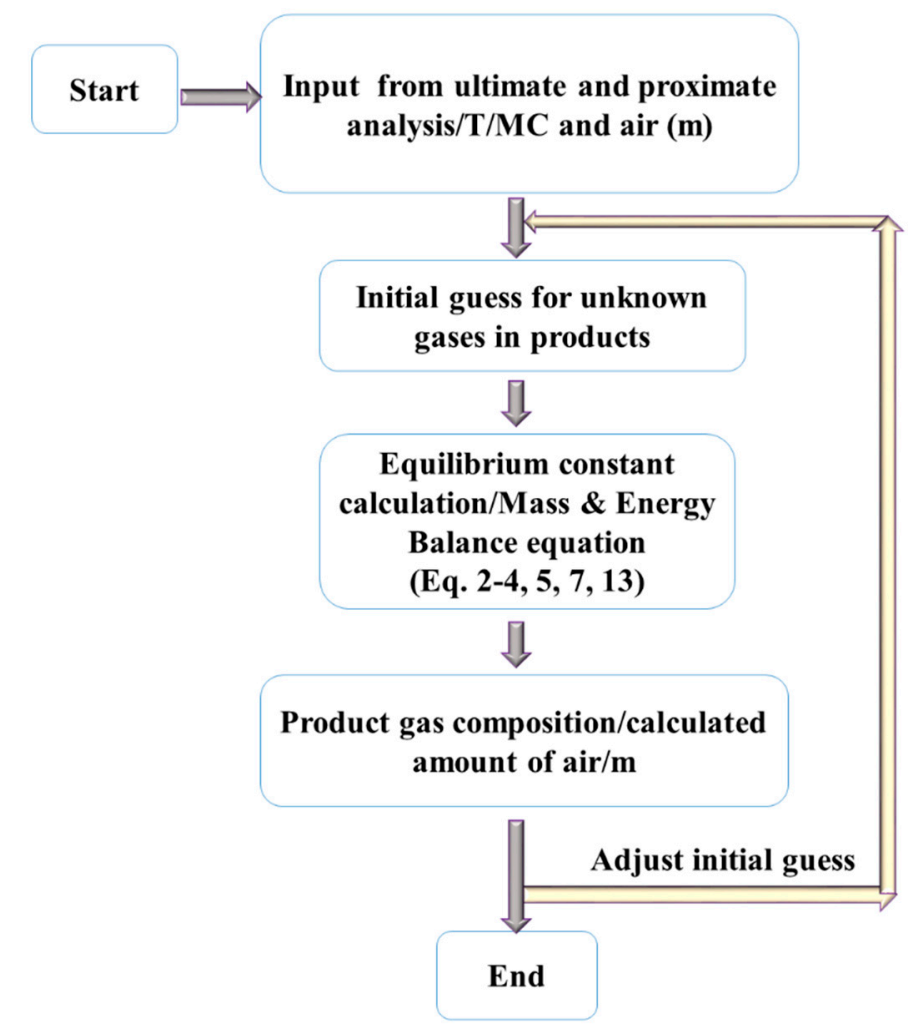

Figure 1. Model algorithm. 
Table 1. Iterative calculation procedure for the models.

\begin{tabular}{cccccc}
\hline Model & Equations (2)-(5), (7), (13), (17), (18) & Equation (16) & $\alpha$ & Cr1 & Cr2 \\
\hline M1 & $\checkmark$ & - & 1 & - & - \\
M2 & $\checkmark$ & $\checkmark$ & $\checkmark$ & - & - \\
M3 & $\checkmark$ & - & 1 & 8.5216 & 0.9617 \\
M4 & $\checkmark$ & $\checkmark$ & $\checkmark$ & 4.7451 & 0.8331 \\
\hline
\end{tabular}

\section{Results and Discussion}

The performance of the proposed model developed in this paper had been tested by the data available from the different experimental studies in the literature. A total of 27 experiments from previous studies were used in this study to fit the models M3 and M4 and to compare the developed models [23]. All the parameters, such as the biomass molecular mass, temperature, and moisture content, were used based on the experimental inputs as reported in the literature. Finally, the root mean square error (RMSE) was calculated for the comparison and to check the accuracy of the developed models, as in Equation (23).

$$
\text { RMSE }=\sqrt{\sum_{i=1}^{N} \frac{(E X P i-M O D E L)^{2}}{N}}
$$

\subsection{Model Modification}

Stoichiometric thermodynamic equilibrium models were optimized on the basis of an overall objective function. An overall RMSE is the objective function in this case which has to be minimized by modifying the correction factors $\mathrm{Cr} 1$ and $\mathrm{Cr} 2$. The optimization routine available in MATLAB, "fminunc", is used to find the optimum correction factor for the equilibrium constant of the water gas shift reaction and the methanation reaction. These correction factors are formulated using the data of 27 experiments from the literature for optimization. As can be seen from Equations (21) and (22), the equilibrium constants are related to the gas composition and the correction factors Cr1 and $\mathrm{Cr} 2$ that modify the equilibrium and adjust the composition of components in the water gas shift and methanation reactions [21]. This improves the prediction of gas compositions for cases where equilibrium may not have been reached.

\subsection{Model Validation}

Four different models have been developed to predict the composition of syngas from the downdraft biomass gasification. The details of all four models are given in Table 1. The first model (M1) was based on the global gasification reaction without including the unconverted carbon in the product and without any equilibrium constant correction factor. The second model (M2) was based on the global gasification reaction, considering the char at the end of the biomass downdraft gasification process, which is represented as $(1-\alpha)$. The third model (M3) was also based on the global gasification reaction, without considering the unconverted carbon in the product and including the equilibrium constant correction factor for the methanation reaction and water gas shift reaction. The fourth model (M4) was also based on the global gasification reaction, considering the unconverted carbon at the end of the biomass downdraft gasification process, which is represented as $(1-\alpha)$, and also considering the correction factor for the methanation reaction and the water gas shift reaction. All the developed four models predicted the syngas composition for any biomass feedstock. The results and the validation of all thermodynamic models (M1-M4) at the specific parameters in the literature are presented in Tables 2 and 3, which show that model M3 gave the minimum error. The literature models mentioned in Tables 2 and 3 are stoichiometric thermodynamic models, including stoichiometric equilibrium models without correction factors $[20,27]$ and one with different correction factors that was calculated with non-linear correlations [23]. In particular, the model of Aydin et al. [23] shows a good fit with this 
set of experimental data, and it also uses correction factors in the equilibrium equations. The ultimate analysis of the biomass used for the validation is given in Table 4. However, in that work non-linear correlations are fitted to calculate $\mathrm{Cr} 1$ and $\mathrm{Cr} 2$, while in this study we show that fixed values for $\mathrm{Cr} 1$ and $\mathrm{Cr} 2$ give a similar or better fit, showing that this simpler model is sufficient for the prediction of gas compositions.

Table 2. Validation of models.

\begin{tabular}{cccccccc}
\hline Comp. & Experiment [35] & Lit. Model [20] & Lit. Model [27] & M1 & M2 & M3 & M4 \\
\hline $\mathrm{H}_{2}$ & 15.23 & 23.39 & 21.06 & 21.7050 & 22.2711 & 18.9336 & 20.5089 \\
$\mathrm{CO}$ & 23.04 & 20.80 & 19.61 & 20.2402 & 19.5681 & 19.5396 & 19.4546 \\
$\mathrm{CO}_{2}$ & 16.42 & 12.31 & 12.01 & 12.3703 & 12.8420 & 14.0165 & 13.5076 \\
$\mathrm{CH}_{4}$ & 1.58 & 0.75 & 0.64 & 0.6620 & 0.6631 & 3.8214 & 2.4086 \\
$\mathrm{~N}_{2}$ & 42.31 & 42.74 & 46.68 & 45.0224 & 44.6557 & 43.6889 & 44.1204 \\
$\mathrm{RMSE}$ & & 4.2277 & 4.1275 & 3.8565 & 4.0194 & 2.7811 & 3.2609 \\
\hline
\end{tabular}

Table 3. Validation of models.

\begin{tabular}{ccccccc}
\hline Comp. & Experiment [36] & Lit. Model [23] & M1 & M2 & M3 & M4 \\
\hline $\mathrm{H}_{2}$ & 11.86 & 10.824 & 13.2116 & 13.2116 & 12.9212 & 12.4944 \\
$\mathrm{CO}$ & 19.89 & 20.576 & 19.8989 & 19.8989 & 19.9888 & 20.5751 \\
$\mathrm{CO}_{2}$ & 11.25 & 12.77 & 11.3755 & 11.3755 & 11.3653 & 10.8779 \\
$\mathrm{CH}_{4}$ & 2.47 & 0.2 & 0.0239 & 0.0239 & 0.1934 & 0.1007 \\
$\mathrm{~N}_{2}$ & 53.95 & 53.52 & 55.4901 & 55.4901 & 55.5313 & 55.9519 \\
$\mathrm{RMSE}$ & & 1.3559 & 1.4281 & 1.4281 & 1.3291 & 1.4582 \\
\hline
\end{tabular}

Table 4. Biomass compositions for the two validation cases in Tables 2 and 3.

\begin{tabular}{ccc}
\hline Components of Biomass & \multicolumn{2}{c}{$\begin{array}{c}\text { Biomass Ultimate Analysis \% } \\
\text { Hazelnut Biomass [36] }\end{array}$} \\
\hline C & 50 & 46.76 \\
H & 6 & 5.76 \\
O & 44 & 45.83 \\
N & 0 & 0.22 \\
S & 0 & 0.67 \\
\hline
\end{tabular}

\subsection{Comparison of Objective Function}

While comparing the RMSE of all the four models in Table 5, it can be observed that the models M1 and M2 showed the highest overall RMSE values-that is, 2.59 and 2.77. Models M3 and M4 are the modification of models M1 and M2 with the optimized correction factor, which reduced the error of the models. The overall RMSE of models M3 and M4 are 2.30 and 2.68, respectively. Among all the thermodynamic models, the M3 model has the lowest RMSE. The comparison of all the cases for each model is presented in Figure 2.

Table 5. The overall root mean square error (RMSE) of all four models.

\begin{tabular}{cc}
\hline Model & Overall RMSE \\
\hline M1 & 2.5970 \\
M2 & 2.7718 \\
M3 & 2.3018 \\
M4 & 2.6859 \\
\hline
\end{tabular}




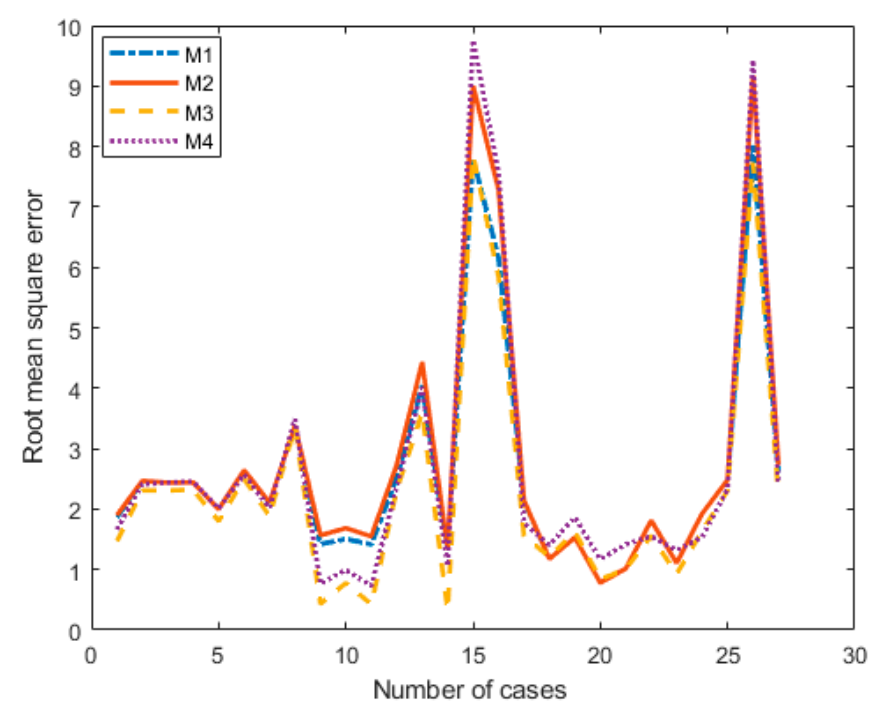

Figure 2. Comparison of the RMSE value.

\subsection{Comparison of the Syngas Composition}

The comparison of the composition of the main species in the syngas can be seen for all 27 experiments and stoichiometric models from Figures 3-7. Figure 3 shows the composition of hydrogen, and it is clearly seen that model M1 and M2 overestimate the composition of the hydrogen for most of the experiments. Meanwhile, the M3 and M4 models predict the close estimation of hydrogen with respect to most of the experiments. Model M3 gives the best prediction among all other equilibrium models. Figures 4 and 5 show the comparison of the composition of carbon monoxide. The results depict that all the thermodynamic models underpredict the composition of carbon monoxide and carbon dioxide. However, the M3 and M4 models overpredict the composition with respect to the unmodified models M1 and M2. Model M3 is in good agreement with the experimental compositions among all other thermodynamic models. Figure 6 shows the comparison of the methane gas composition. Methane gas is produced in a very small amount in the biomass gasification process. Thus, the concern with methane is not very important in the biomass air gasification process. Model M1 and model M2 give a close estimation while comparing with the experimental composition of methane gas. However, M3 and M4 overpredict the composition of the syngas for some experiments. Hydrogen, carbon monoxide, and carbon dioxide are the major part of the syngas. Therefore, methane prediction has not much importance as compared to the major components of the syngas. Figure 7 shows the composition of the nitrogen gas for all the models and experiments. In this study, it is assumed that nitrogen does not participate in the gasification reaction. On the other hand, practically this is not possible because, in the gasification process, some impurities of nitrogen compounds are also part of the product which are very negligible. These thermodynamic models mostly give a closer estimation of nitrogen gas. Before going to the complex and costly experimental set up, we can use model M3 to estimate the expected syngas composition from the ultimate analysis and moisture contents of biomass. This model has the ability to predict the product composition with varying parameters, such as temperature, equivalence ratio, and moisture content. These models can be used for the integrated combined heat and power generation models. 


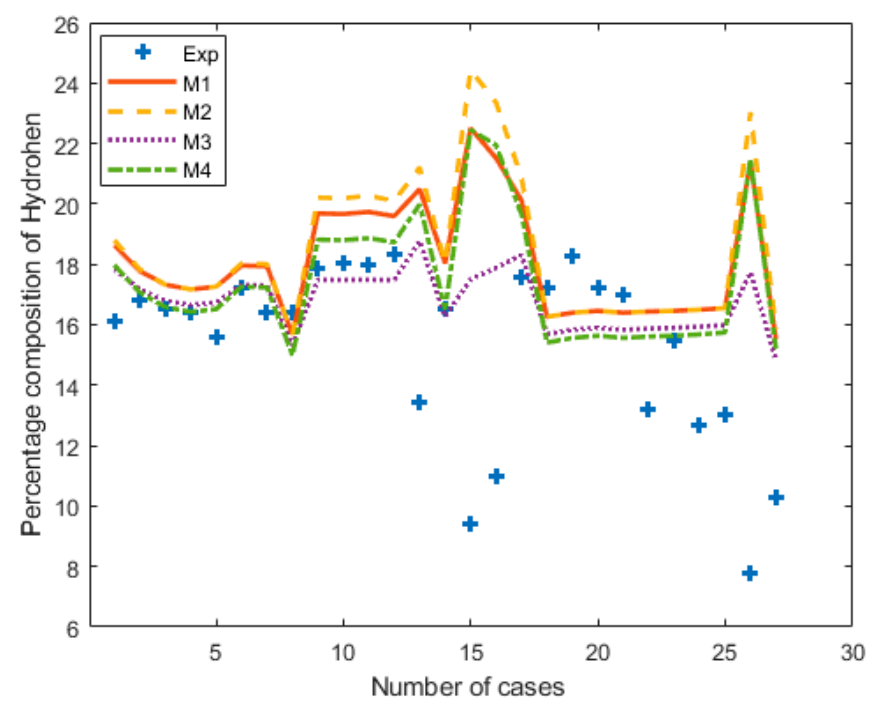

Figure 3. Comparison of the hydrogen composition with experiments and models.

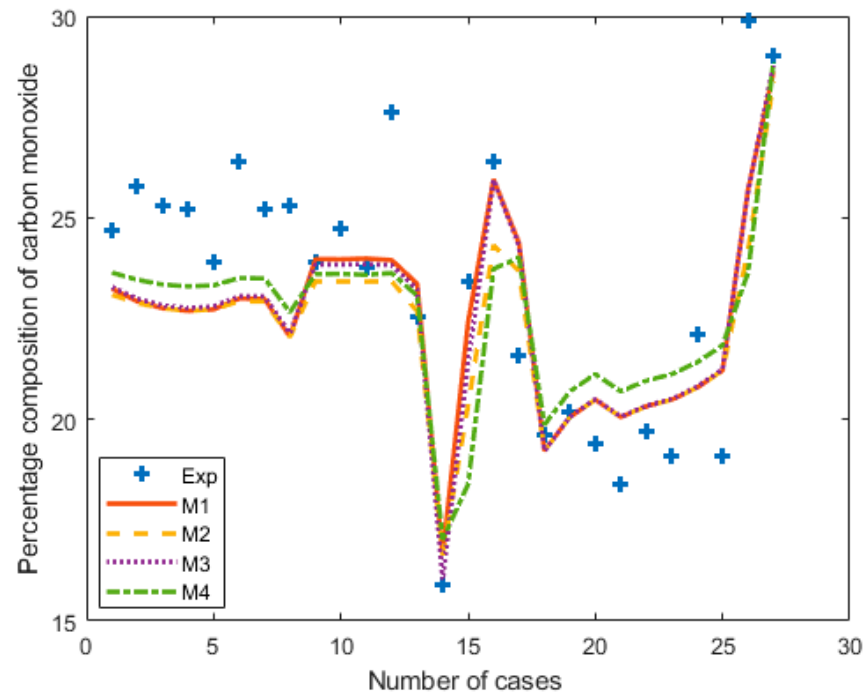

Figure 4. Comparison of the carbon monoxide composition with experiments and models.

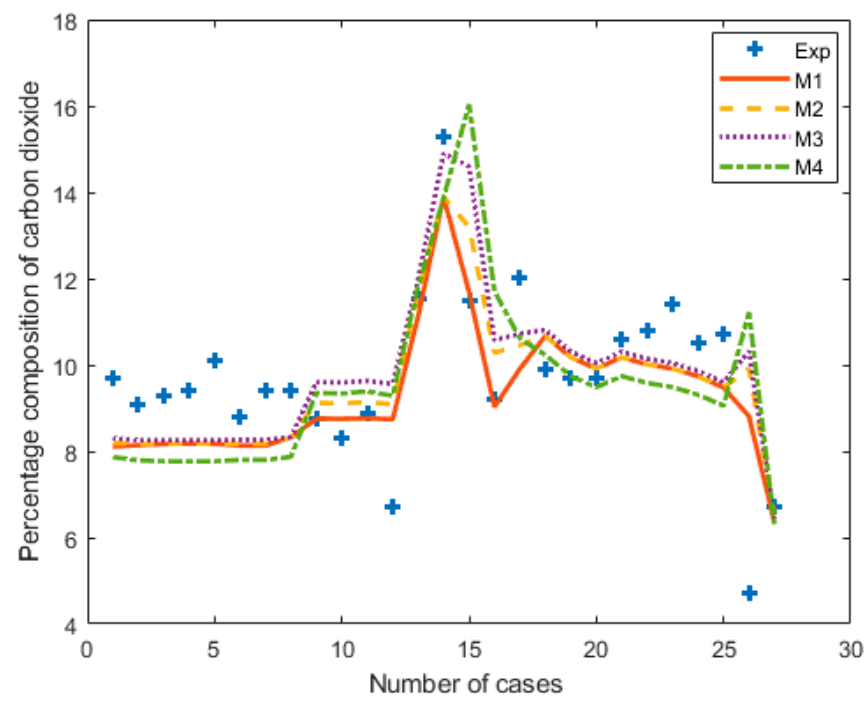

Figure 5. Comparison of the carbon dioxide composition with experiments and models. 


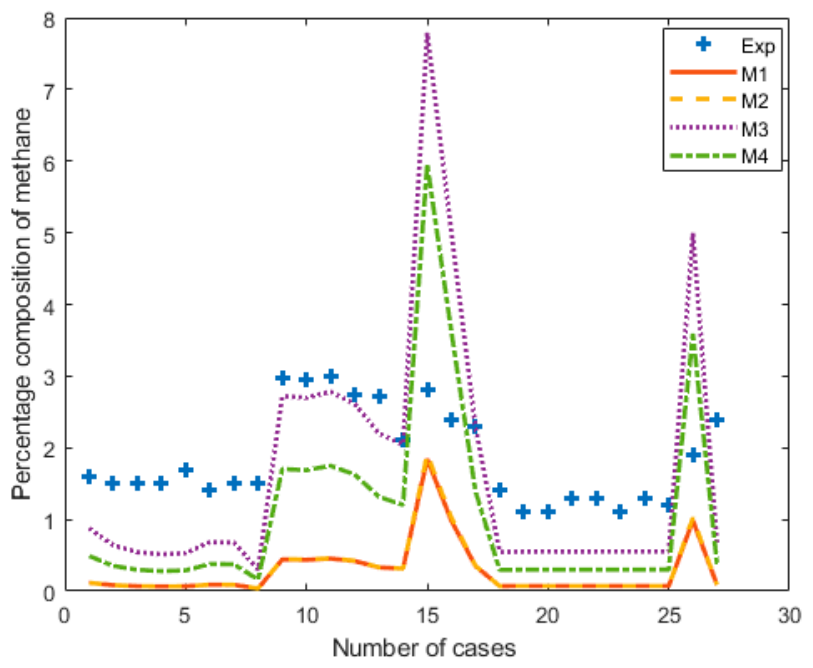

Figure 6. Comparison of the methane composition with experiments and models.

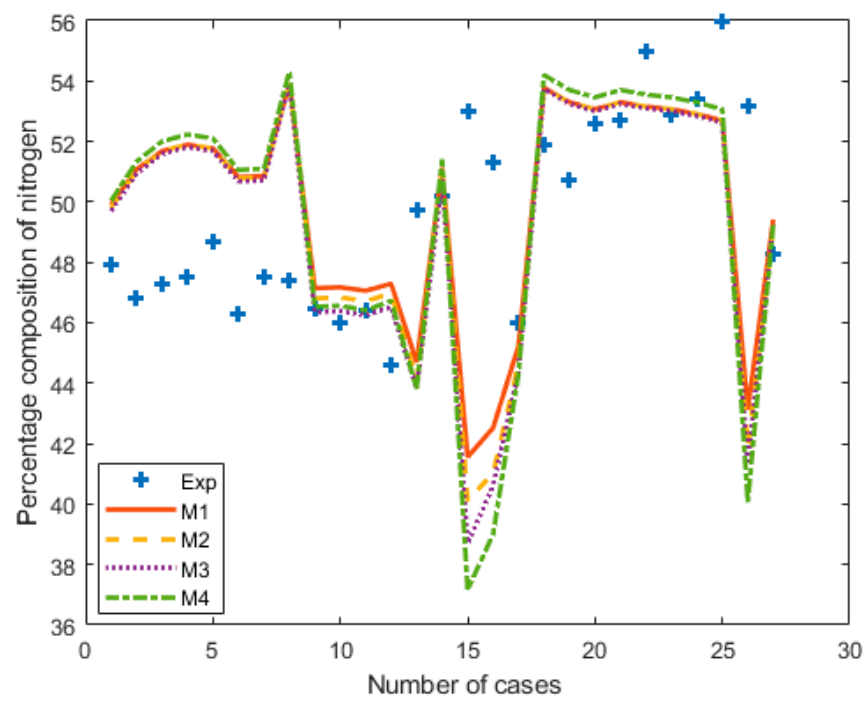

Figure 7. Comparison of the nitrogen composition with experiments and models.

\section{Conclusions}

In this study, stoichiometric thermodynamic equilibrium modelling for biomass gasification has been performed. The analysis has been carried out for the prediction performance to predict the syngas composition. The correction factors for the equilibrium constants of the water gas shift reaction and the methanation reaction have been optimized and generated using the data from 27 experimental values published in the literature. The models are formulated and optimized in MATLAB. The model M3 shows the lowest RMSE among all other thermodynamic equilibrium models. These models have the ability to predict the syngas composition for any available biomass feedstock. These models also have the ability to estimate the performance of biomass gasification for different operating conditions, such as temperature and moisture contents.

The correction factors utilized in these modified models (M3 and M4) are parameters that are used to multiply with the equilibrium constants (see Equations (21) and (22)) in order to improve the accuracy of the models and better fit the experimental gas compositions. While some other studies have also considered correction factors of this sort, previous studies have fitted parameters using fewer experimental studies, such as the work of Jarungthammachote and Dutta using 11 experimental studies [21], and so are expected to be less accurate for wide ranges of different biomasses. A more complex model was also presented by Aydin et al. [23], where fitted non-linear correlations are used 
to calculate the correction factors. However, in this study we show that similar results and model accuracies can be achieved with a simpler model where the correction factors are fixed parameters.

Future work should consider steam gasification for the enriched hydrogen syngas and hydrogasification performed with hydrogen produced for the production of enriched methane gas. This should be done by considering the dioxins and reduced toxic emissions. More complex models could also be proposed involving more fitted parameters in order to improve the prediction accuracy of the models. For example, this could be done by including the dependence on different operating conditions or switching to a non-stoichiometric equilibrium model which could potentially have large numbers of fitted parameters. In addition, the minor gas products and trace products could also be included to give more detailed output. This could also consider the production of toxic emissions, including dioxins and furans.

Author Contributions: The author contributions were as follows: Conceptualization, H.M.U.A. and M.B.; methodology, H.M.U.A. and M.B.; validation, H.M.U.A.; data curation, H.M.U.A.; writing-original draft preparation, H.M.U.A.; writing-review and editing, M.B. and S.J.P.; supervision, M.B. All authors have read and agreed to the published version of the manuscript.

Funding: This research received no external funding

Acknowledgments: Support is acknowledged from the SRD scholarship, Dongguk University, Seoul, South Korea.

Conflicts of Interest: The authors declared that there is no conflict of interest for this work.

\section{Nomenclature}

C

$H$

O

N

$S$

Ash

ER

$a$

b

$w$

m

$\rho$

$x_{i}$

$\alpha$

$\mathrm{C}_{p i}$

$H_{f-i}^{0}$

T

To

$\mathrm{K}_{1, \mathrm{CH}_{4}}$

$K_{2, w g s}$
Carbon mass fraction from the ultimate analysis

Hydrogen mass fraction from the ultimate analysis

Oxygen mass fraction from the ultimate analysis

Nitrogen mass fraction from the ultimate analysis

Sulphur mass fraction from the ultimate analysis

mass fraction of ash in biomass feedstock

Equivalence ratio

number of hydrogen atoms per carbon atom in biomass molecule

number of oxygen atoms per carbon atoms in biomass molecule

moisture of biomass [mole/mole of biomass]

moles of oxygen [mole/mole of biomass]

nitrogen to oxygen molar ratio in the oxidant

coefficients of the product constituent

actual fraction of $C$ participating in thermodynamic equilibrium reactions

specific heat capacity of component $i$

The heat of formation of component $i$

Gasification temperature

Entering temperature of all the reactants into the gasifier

Equilibrium constant of the methanation reaction

Equilibrium constant of the water gas shift reaction

\section{References}

1. Sansaniwal, S.; Pal, K.; Rosen, M.; Tyagi, S. Recent advances in the development of biomass gasification technology: A comprehensive review. Renew. Sustain. Energy Rev. 2017, 72, 363-384. [CrossRef]

2. Qyyum, M.A.; Yasin, M.; Nawaz, A.; He, T.; Ali, W.; Haider, J.; Qadeer, K.; Nizami, A.-S.; Moustakas, K.; Lee, M. Single-Solution-Based Vortex Search Strategy for Optimal Design of Offshore and Onshore Natural Gas Liquefaction Processes. Energies 2020, 13, 1732. [CrossRef]

3. Basu, P. Biomass Gasification and Pyrolysis: Practical Design and Theory; Academic Press: Cambridge, MA, USA, 2010.

4. Ferreira, S.; Monteiro, E.; Brito, P.; Vilarinho, C. A holistic review on biomass gasification modified equilibrium models. Energies 2019, 12, 160. [CrossRef] 
5. Tavares, R.; Monteiro, E.; Tabet, F.; Rouboa, A. Numerical investigation of optimum operating conditions for syngas and hydrogen production from biomass gasification using Aspen Plus. Renew. Energy 2020, 146, 1309-1314. [CrossRef]

6. Marcantonio, V.; Bocci, E.; Monarca, D. Development of a chemical quasi-equilibrium model of biomass waste gasification in a fluidized-bed reactor by using Aspen Plus. Energies 2020, 13, 53. [CrossRef]

7. Wang, X.; Zheng, W.; Ma, Y.; Ma, J.; Ming Gao, Y.; Zhang, X.; Li, J. Gasification filter cake reduces the emissions of ammonia and enriches the concentration of phosphorous in Caragana microphylla residue compost. Bioresour. Technol. 2020, 315, 123832. [CrossRef]

8. Tosti, S.; Sousa, M.A.; Buceti, G.; Madeira, L.M.; Pozio, A. Process analysis of refuse derived fuel hydrogasification for producing SNG. Int. J. Hydrogen Energy 2019, 44, 21470-21480. [CrossRef]

9. Shayan, E.; Zare, V.; Mirzaee, I. On the use of different gasification agents in a biomass fueled SOFC by integrated gasifier: A comparative exergo-economic evaluation and optimization. Energy 2019, 171, 1126-1138. [CrossRef]

10. Patra, T.K.; Sheth, P.N. Biomass gasification models for downdraft gasifier: A state-of-the-art review. Renew. Sustain. Energy Rev. 2015, 50, 583-593. [CrossRef]

11. Liu, H.; Cattolica, R.J.; Seiser, R. Operating parameter effects on the solids circulation rate in the CFD simulation of a dual fluidized-bed gasification system. Chem. Eng. Sci. 2017, 169, 235-245. [CrossRef]

12. Kraft, S.; Kirnbauer, F.; Hofbauer, H. CPFD simulations of an industrial-sized dual fluidized bed steam gasification system of biomass with $8 \mathrm{MW}$ fuel input. Appl. Energy 2017, 190, 408-420. [CrossRef]

13. Pradhan, P.; Mahajani, S.; Arora, A. Evaluating the Sensitivity of Biomass Feedstocks to Producer Gas Composition Using Stoichiometric Equilibrium Model. In Advances in Energy Research; Springer: Berlin/Heidelberg, Germany, 2020; Volume 2, pp. 715-723.

14. Hejazi, B.; Grace, J.R.; Bi, X.; Mahecha-Botero, A. Kinetic Model of Steam Gasification of Biomass in a Bubbling Fluidized Bed Reactor. Energy Fuels 2017, 31, 1702-1711. [CrossRef]

15. Acharya, B.K.; Pathak, H.; Mohana, S.; Shouche, Y.; Singh, V.; Madamwar, D. Kinetic modelling and microbial community assessment of anaerobic biphasic fixed film bioreactor treating distillery spent wash. Water Res. 2011, 45, 4248-4259. [CrossRef] [PubMed]

16. Farid, M.M.; Jeong, H.J.; Hwang, J. Kinetic study on coal-biomass mixed char co-gasification with $\mathrm{H} 2 \mathrm{O}$ in the presence of H2. Fuel 2016, 181, 1066-1073. [CrossRef]

17. Mendiburu, A.Z.; Carvalho, J.A.; Coronado, C.J.R. Thermochemical equilibrium modeling of biomass downdraft gasifier: Stoichiometric models. Energy 2014, 66, 189-201. [CrossRef]

18. George, J.; Arun, P.; Muraleedharan, C. Stoichiometric Equilibrium Model Based Assessment of Hydrogen Generation through Biomass Gasification. Procedia Technol. 2016, 25, 982-989. [CrossRef]

19. Gambarotta, A.; Morini, M.; Zubani, A. A non-stoichiometric equilibrium model for the simulation of the biomass gasification process. Appl. Energy 2017, 227, 119-127. [CrossRef]

20. Azzone, E.; Morini, M.; Pinelli, M. Development of an equilibrium model for the simulation of thermochemical gasification and application to agricultural residues. Renew. Energy 2012, 46, 248-254. [CrossRef]

21. Jarungthammachote, S.; Dutta, A. Thermodynamic equilibrium model and second law analysis of a downdraft waste gasifier. Energy 2007, 32, 1660-1669. [CrossRef]

22. Costaa, M.; La Villetta, M.; Massarottia, N. Optimal tuning of a thermo-chemical equilibrium model for downdraft biomass gasifiers. Chem. Eng 2015, 43, 439-444.

23. Aydin, E.S.; Yucel, O.; Sadikoglu, H. Development of a semi-empirical equilibrium model for downdraft gasification systems. Energy 2017, 130, 86-98. [CrossRef]

24. Gautam, G.; Adhikari, S.; Bhavnani, S. Estimation of biomass synthesis gas composition using equilibrium modeling. Energy Fuels 2010, 24, 2692-2698. [CrossRef]

25. Pradhan, P.; Arora, A.; Mahajani, S.M. A semi-empirical approach towards predicting producer gas composition in biomass gasification. Bioresour. Technol. 2019, 272, 535-544. [CrossRef] [PubMed]

26. Jayah, T.; Aye, L.; Fuller, R.J.; Stewart, D. Computer simulation of a downdraft wood gasifier for tea drying. Biomass Bioenergy 2003, 25, 459-469. [CrossRef]

27. Zainal, Z.; Ali, R.; Lean, C.; Seetharamu, K. Prediction of performance of a downdraft gasifier using equilibrium modeling for different biomass materials. Energy Convers. Manag. 2001, 42, 1499-1515. [CrossRef] 
28. Zainal, Z.; Rifau, A.; Quadir, G.; Seetharamu, K. Experimental investigation of a downdraft biomass gasifier. Biomass Bioenergy 2002, 23, 283-289. [CrossRef]

29. Altafini, C.R.; Wander, P.R.; Barreto, R.M. Prediction of the working parameters of a wood waste gasifier through an equilibrium model. Energy Convers. Manag. 2003, 44, 2763-2777. [CrossRef]

30. Anukam, A.; Mamphweli, S.; Meyer, E.; Okoh, O. Computer simulation of the mass and energy balance during gasification of sugarcane bagasse. J. Energy 2014, 2014, 1-9. [CrossRef]

31. Smith, J.M. Introduction to Chemical Engineering Thermodynamics; ACS Publications: Washington, DC, USA, 1950.

32. de Souza-Santos, M.L. Solid Fuels Combustion and Gasification: Modeling, Simulation; CRC Press: Boca Raton, FL, USA, 2010.

33. Channiwala, S.; Parikh, P. A unified correlation for estimating HHV of solid, liquid and gaseous fuels. Fuel 2002, 81, 1051-1063. [CrossRef]

34. Basu, P. Chapter 5-Gasification theory and modeling of gasifiers. In Biomass Gasification and Pyrolysis: Practical Design and Theory; Academic Press: Cambridge, MA, USA, 2010.

35. Alauddin, Z.A.Z. Performance and characteristics of a biomass gasifier system. Ph.D. Thesis, University of Wales, Cardiff, Wales, UK, 1996.

36. Dogru, M.; Howarth, C.; Akay, G.; Keskinler, B.; Malik, A. Gasification of hazelnut shells in a downdraft gasifier. Energy 2002, 27, 415-427. [CrossRef]

Publisher's Note: MDPI stays neutral with regard to jurisdictional claims in published maps and institutional affiliations.

(C) 2020 by the authors. Licensee MDPI, Basel, Switzerland. This article is an open access article distributed under the terms and conditions of the Creative Commons Attribution (CC BY) license (http://creativecommons.org/licenses/by/4.0/). 